\title{
Probabilistic modeling of vulnerability of road infrastructures to floods
}

\author{
Marco Uzielli, ${ }^{1, a}$, Bjørn Vidar Vangelsten ${ }^{1}$ and Unni Eidsvig ${ }^{1}$ \\ ${ }^{1}$ Norwegian Geotechnical Institute, Postboks 3930 Ullevål Stadion, 0806 Oslo, Norway
}

\begin{abstract}
Factors which contribute to the vulnerability of physical elements such as road infrastructures to a natural hazard such as a flood event are pervaded by uncertainty due to the complexity of the hazard, of the vulnerable infrastructure and of their physical interaction. In the context of risk management efforts, it is conceptually correct to explicitly address this uncertainty and to parameterize the criticality of the vulnerable element and, consequently, an explicit target degree of conservatism and reliability in risk assessment and mitigation strategies. This paper illustrates the results of the probabilistic characterization of the vulnerability of road infrastructures to flood events for two areas in South-Eastern Norway. Flood intensity and road vulnerability serve as inputs to an analytical model, which expresses the latter as a function of the former with respect to a user-set level of probability of exceedance. Deterministic and probabilistic vulnerability estimates are compared quantitatively, and the results are assessed and analyzed critically.
\end{abstract}

\section{Introduction}

The quantitative modeling of vulnerability is a central module in quantitative risk assessment of critical infrastructures to extreme weather events. Vulnerability is most often estimated deterministically, i.e., with no explicit modelling, processing and quantification of uncertainty. It is well known, however, that the factors which contribute to the vulnerability of physical elements such as road infrastructures to a natural hazard such as a flood event are pervaded by uncertainty due to the inherent complexity of the hazard, that of the vulnerable infrastructure and of their physical interaction. The deterministic approach to the quantification of vulnerability, in which uncertainties are not explicitly specified, processed and reported, thus hinders a comprehensive assessment of the fragility of the vulnerable element. Hence, such an approach may not provide optimal support for informed risk management purposes.
This paper illustrates the results of the probabilistic characterization of the vulnerability of road infrastructures to flood events for two counties in SouthEastern Norway. Damage surveys from flood events of 2011 are used jointly with peak 24-hour rainfall data to parameterize loss and hazard intensity, respectively. Vulnerability is defined quantitatively hereinafter as the ratio of measured economic loss to the total cost of reconstruction of the road infrastructures. Such definition is also valid for other definitions of vulnerability representing degree of loss. Intensity and vulnerability serve as inputs to a reference analytical vulnerability model, which expresses quantitatively the relationship between the two.

Model parameters are first calibrated deterministically using generalized least-squares regression. Subsequently, vulnerability is characterized probabilistically through quantile regression. Quantile regression (e.g. Yu et al. 2003) allows the calibration of model parameters with reference to a user-defined probability of non-

\footnotetext{
${ }^{\mathrm{a}}$ Corresponding author: $\underline{\operatorname{muz} @ \text { ngi.no }}$
} 
exceedance. Through this approach, it is possible to calibrate model parameters corresponding to a desired level of conservatism in vulnerability estimates, thereby obtaining "characteristic" vulnerability functions. Such functions reflect the user-assigned qualitative degree of criticality of the vulnerable infrastructure, thereby allowing a full probabilistic flood risk assessment.

\section{Quantitative vulnerability model}

A vulnerability model is proposed in the following functional form:

$$
V=V_{u b} \cdot\left\{1-\exp \left[-\left(\frac{I}{A}\right)^{B}\right]\right\}
$$

in which:

- $V_{u b}$ is the inherent upper-bound vulnerability, i.e., the maximum value which vulnerability can take as a consequence of its definition. For example, when considering direct physical damage to critical infrastructure (CI) and loss is measured as repair cost, vulnerability can be given by the ratio of repair cost to replacement cost. In such case, $V_{u b}=1$;

- $I$ is the intensity of the extrme weather event (EW E), efficiently parameterized in terms of an EWE's physical attribute (e.g., wind speed, rainfall intensity, etc.) or of the event's presumed return period.

- A is the location parameter, describing the value of intensity corresponding to the maximum vulnerability gradient. The location parameter also corresponds to the abscissa of the flex of the vulnerability function;

- B is the brittleness parameter, describing the rapidity with which vulnerability increases with increasing EWE intensity. High values of B correspond to rapidly increasing vulnerability, whereas low values of B correspond to a gradual increase in vulnerability.

The vulnerability model in Eq. (1) allows for considerable flexibility in the intensity-vulnerability relationship, and is thus able to accommodate different behaviors through variations in the model parameters $\mathrm{A}$

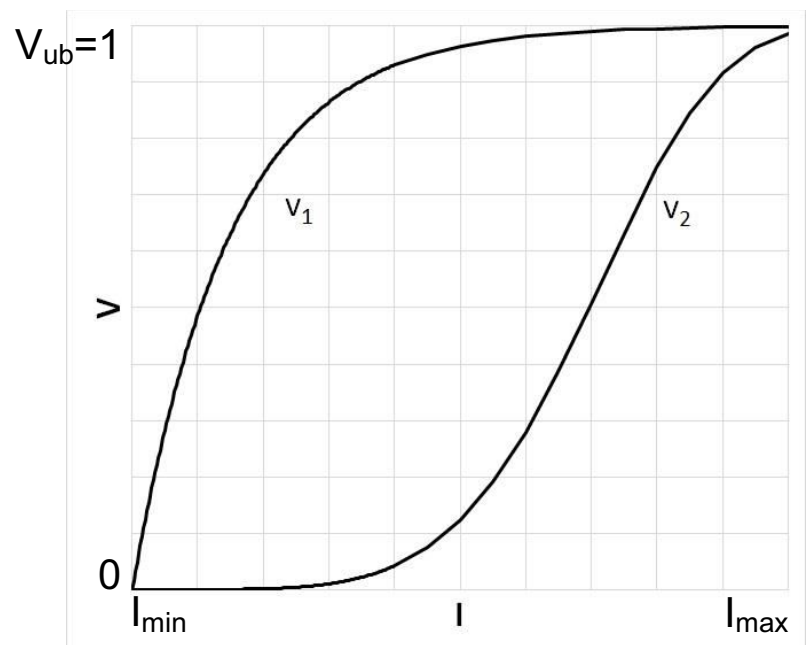

Figure 1. Comparative plot of two vulnerability functions with $V_{u b}=1$ and B. Fig. 1 illustrates comparatively two very different intensity-vulnerability relationships: vulnerability curve V1 displays a rapid increase for low intensity values, and a progressive decrease in gradient with increasing intensity. Vulnerability curve V2 corresponds to a scenario in which vulnerability remains low for low intensity values, then increases significantly for intermediate to high intensity values.

Though vulnerability can be conceptually defined as the expected degree of loss (damage), with respect to the maximum possible degree, suffered by one or more vulnerable elements as the consequence of the impact of a hazardous event with a given intensity level, the operational definition of vulnerability will vary depending on type of $\mathrm{CI}$ and the vulnerable element under investigation. Some examples of impact variables could be:

- Down time: Down time of the CI could for example be normalised by the reconstruction time from scratch of the CI component that was impacted

- Number of people losing CI service (for a longer duration than a threshold time period): Number of impacted people could be normalised by the number of people being serviced by the $\mathrm{CI}$ in question

- Repair cost: Repair cost could be normalised by the cost of a full reconstruction of the $\mathrm{CI}$ in question

- Degree of service loss of the CI. An example could be a road that has reduced capacity due to an EWE.

Figure $2 \mathrm{a}$ and Figure $2 \mathrm{~b}$ illustrate qualitatively the effects of variations of the model parameters A (location) and $\mathrm{B}$ (brittleness), respectively, on vulnerability with respect to prior states $A_{0}$ and $B_{0}$.

While increases in the location parameter $A$ are univocally beneficial in terms of decreasing vulnerability for any given intensity level, a qualitative reasoning on the brittleness parameter B suggests that an increase in the brittleness parameter leads to a reduction in vulnerability for intensity values lower than the location parameters, while vulnerability increases for intensity values higher than the location parameter (see Figure 3 ).

This non-uniform effect, in planning risk mitigation actions, to assess whether mitigation is envisaged primarily for low or high intensity ranges. This in turn relates to return periods, with lower intensities corresponding to lower return periods and higher intensities to higher return periods. Risk mitigation could thus be pursued quantitatively, with the aid of this model, using performance-based criteria for vulnerability mitigation and referring to specific life cycle durations for a CI. Target design vulnerability values could be set for given levels of expected intensity in order to pursue a rational cost-benefit analysis. 
(a)

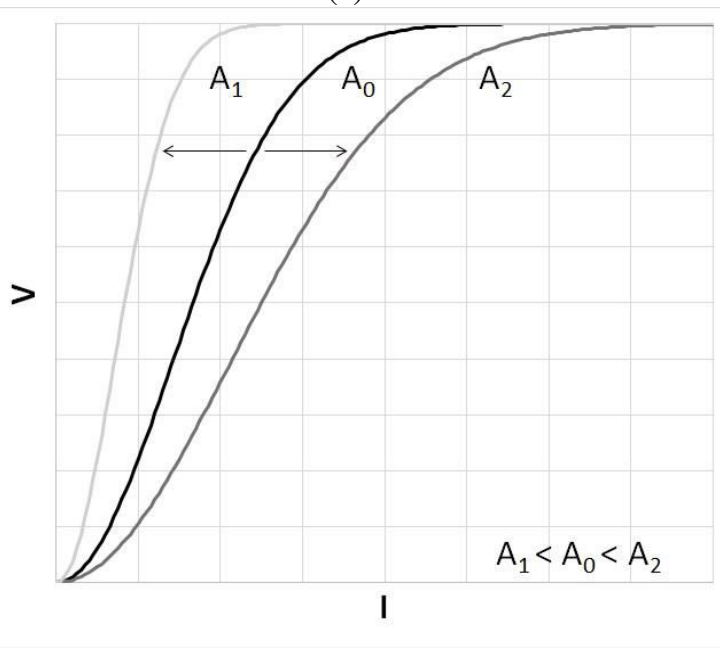

(b)

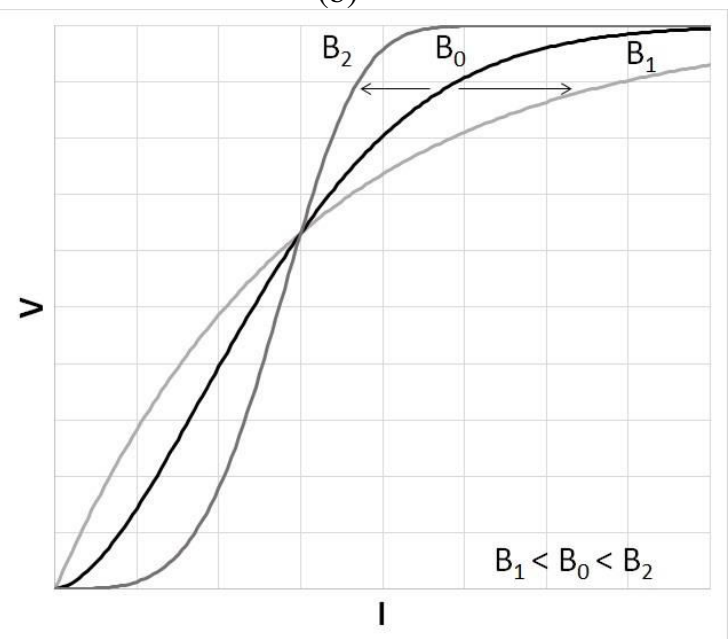

Figure 2. Qualitative explanation of the effects of model parameters $A$ and $B$ on the vulnerability model

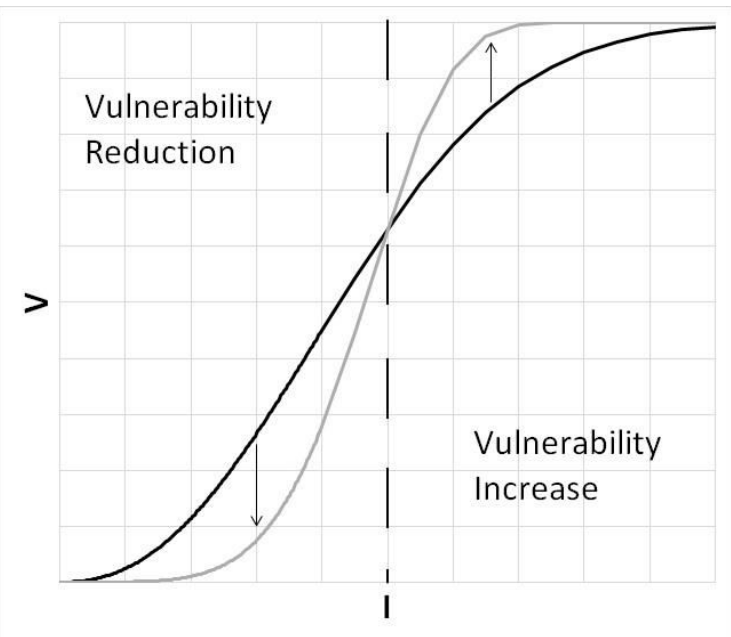

Figure 3. Non-uniformity of the effect of variations in the brittleness parameter $B$ on the vulnerability model

\section{Flood damage in the counties of Oppland and Hedmark}

The counties of Oppland and Hedmark in the eastern part of Norway experienced two very similar flood events in 2011 and 2013. They were both caused by snow melt in the mountains combined with intense rainfall. The descriptions of the two events are accounts taken mainly from [1-4]. Figure 4 shows flood reports from the peak of the two events, indicating a large number of flood and landslide damages.

\subsection{The June 2011 events}

During the Spring of 2011, the Norwegian Water Resources and Energy Directorate (NVE) assessed the likelihood of a large spring floods as small because of relatively little snow in the mountains and early snow melt in the first half of April. But at the end of May there was still snow in the mountains, and in addition heavy rainfall saturated the ground and filled groundwater reservoirs. In the period 6th - 12th June, significant rainfall occurred in several places simultaneously as high temperature led to strong snowmelt in the mountains. NVE issued the first flood warning on Monday 6 June, and upgraded the warning to "major flood" level on June 10. Several main rivers reached 100-year flood level, however it was the flood level in side tributaries and the large number of landslides that caused the most significant impacts. The main road through Østerdalen, Highway 3, was closed on the night of June 10. Subsequently, an increasing number of roads closed out overnight and on the morning of June 10 both in the counties of Hedmark and Oppland. Early on June 10 the police received the first reports of flood damage, closed roads and people who evacuated themselves. Throughout the day on June 10, it became clear that conditions stabilized in Hedmark. However, in Oppland and especially in the region of Gudbrandsdalen, flood levels increased and damages caused by floods and landslides were reported through the day. The European main road through Gudbrandsdalen, E6, was closed in one location due to debris flows. Eventually, it also closed at several places during the period 10-14 June. In the county of Oppland more than 30 roads were closed due to flooding and landslides. In Hedmark, up to seven roads were closed at the same time due to the flood. In addition, the north south railroad, Dovrebanen, was closed. More than 270 people were evacuated over from their homes, mainly in Oppland. In addition, an unknown number of people evacuated and accommodated themselves privately . Overall damage costs were estimated to 800 million Norwegian Kroner (NOK).

\subsection{The May 2013 events}

The winter and spring of 2013 were cold and relatively dry with mostly less snow than normal in Eastern Norway. On May 3, a flood alert was issued by the Norwegian Water Resources and Energy Directorate (NVE). Significantly warmer weather was forecasted 


\begin{tabular}{|c|c|c|c|c|c|c|c|c|}
\hline Case No & County & $\operatorname{Road} \mathbf{N}^{\circ}$ & Segment & River & $\begin{array}{c}\mathbf{T}_{\mathrm{R}}{ }^{\mathrm{a}} \\
\text { [Years] }\end{array}$ & $\begin{array}{c}\text { Length } \\
{[\mathrm{km}]}\end{array}$ & Damage $^{b}$ & $\begin{array}{c}\text { Damage } \\
\text { cost } \\
{[\mathrm{KNOK}]}\end{array}$ \\
\hline 01 & Oppland & 255 & Lillehammer-Gausdal & Sjoa & 100 & 105 & $\mathrm{~A}, \mathrm{~B}, \mathrm{~F}$ & 4300 \\
\hline 02 & Oppland & 440 & Ressetdalen & Sjoa & 100 & 24 & $\mathrm{~B}, \mathrm{C}$ & 2500 \\
\hline 03 & Oppland & 257 & Skjærdalen & Sjoa & 100 & 31 & $\mathrm{D}$ & 3500 \\
\hline 04 & Oppland & 315 & Follebu - Svingvoll & Gausa & 100 & 18 & B & 5000 \\
\hline 05 & Oppland & 318 & Dalsvingen - kryss fv 254 & Gausa & 100 & 21 & $\mathrm{C}$ & 2200 \\
\hline 06 & Oppland & 436 & Otta - Vågå & Otta & 100 & 32 & $\mathrm{~B}, \mathrm{E}$ & 1100 \\
\hline 07 & Oppland & 417 & Kvam - Sjoa & Gudbrandsdalslågen & 100 & 12 & $\mathrm{C}, \mathrm{J}$ & 5000 \\
\hline 08 & Oppland & 403 & Sørjordet-Gring & Gudbrandsdalslågen & 100 & 3 & $\mathrm{C}, \mathrm{J}$ & 3000 \\
\hline 09 & Oppland & 438 & Vågårustvegen & Otta / Gudbrandsdalslågen & 100 & 18 & $\mathrm{C}$ & 4000 \\
\hline 10 & Hedmark & 207 & Finnstad - Kynnberget & Glomma (Elverum) & 5 & 11 & $\mathrm{H}$ & 908 \\
\hline 11 & Hedmark & 535 & Elverum - Bruberg & Glomma (Elverum) & 5 & 32 & $\mathrm{~A}, \mathrm{G}$ & 1064 \\
\hline
\end{tabular}

a Return period of estimated river discharge (in yrs)

b A: Ditch; B: Landslide; C: Erosion; D: Damage to concrete construction; E: Settlements; F: Damage to surface layer; G: Culverts; H: Slope failure; J: Undermining/erosion

${ }^{\mathrm{c}}$ http://www.vegvesen.no/Om+Statens+vegvesen/Presse/Nyheter/Nasjonalt/s\%C3\%A5-mye-koster-det-\%C3\%A5-bygge-en-meter-vei

Table 1. Road segments for which flood return period and monetary damage is known after the 2011 flooding. Source: NPRA (2012), Kleivane (2011)

(with potential snow melt in the mountains) in combination with intense rainfall. This message was followed up with a total of 27 warning messages in the period May 14 to June 4, including a notification of "major flood" on 21 May. The flood event culminated on 21 May in Hedmark county and on 22 May in Oppland county.
Torrential rain created flooding in tributaries and debris flows in many places, and buildings and infrastructure were affected. Evacuation was initiated in several municipalities. Damaged and closed roads and rail lines reduced the mobility. Local failures in the mobile communication network created challenges for (a) Flood report from June 10, 2011

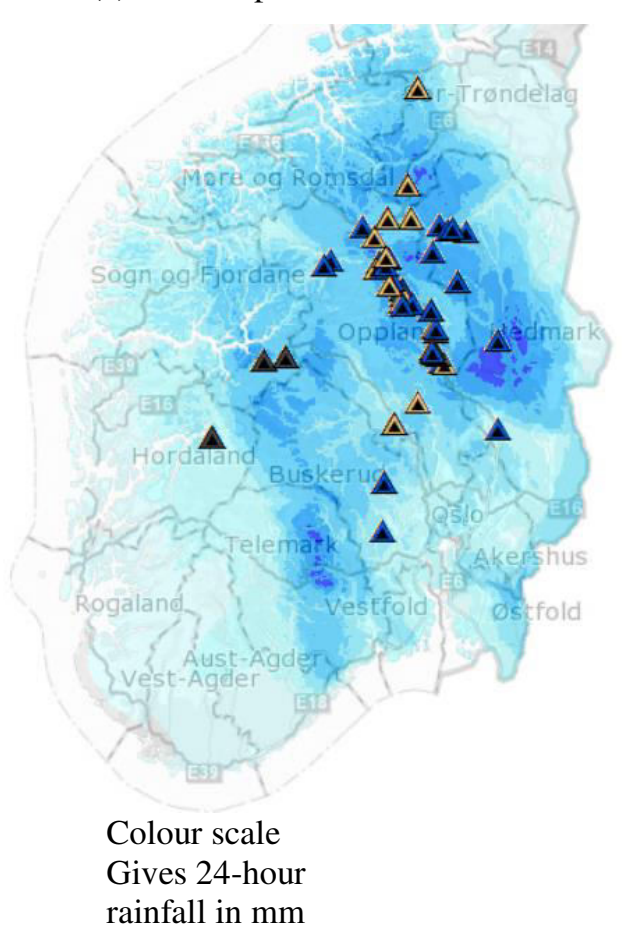

(b) Flood report from May 23, 2013

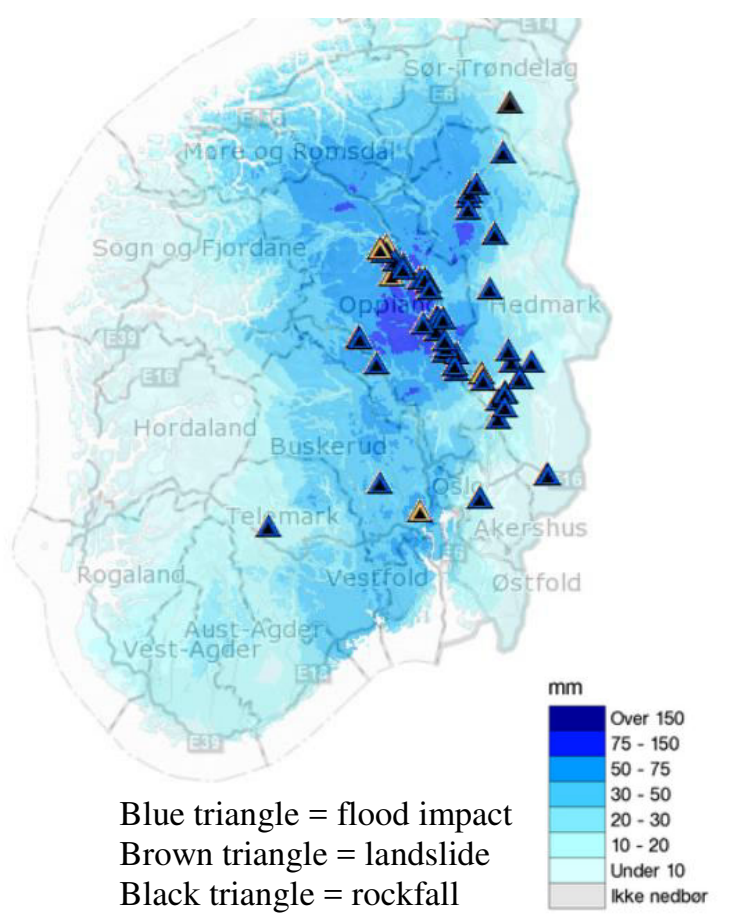

Figure 4. Flood reports from the peak of the two flood events in 2011 and 2013. The counties of Oppland and Hedmark were most impacted during both events. Source: www.varsom.no 


\begin{tabular}{clcc}
\hline Case & River & $\boldsymbol{T}_{\boldsymbol{R}}$ & $\boldsymbol{I}$ \\
\hline 01 & Sjoa & 100 & 2.00 \\
02 & Sjoa & 100 & 2.00 \\
03 & Sjoa & 100 & 2.00 \\
04 & Gausa & 100 & 2.00 \\
05 & Gausa & 100 & 2.00 \\
06 & Otta & 100 & 2.00 \\
07 & Gudbrandsdalslågen & 100 & 2.00 \\
08 & Gudbrandsdalslågen & 100 & 2.00 \\
09 & Otta / Gudbrandsdalslågen & 100 & 2.00 \\
10 & Glomma (Elverum) & 5 & 0.70 \\
11 & Glomma (Elverum) & 5 & 0.70 \\
12 & Glomma (Nye Stai) & 2 & 0.30 \\
\hline
\end{tabular}

Table 2. Intensity values

\begin{tabular}{cccccc}
\hline case & $\begin{array}{c}\text { Length } \\
{[\mathbf{k m}]}\end{array}$ & $\begin{array}{c}\text { Total cost } \\
{[\mathbf{M N O K}]}\end{array}$ & Damage & $\begin{array}{c}\text { Damage } \\
\text { cost } \\
{[\text { KNOK] }}\end{array}$ & V \\
\hline 01 & 105 & 7350 & A,B,F & 4300 & 0.0006 \\
02 & 24 & 1680 & B,C & 2500 & 0.0015 \\
03 & 31 & 2170 & D & 3500 & 0.0016 \\
04 & 18 & 1260 & B & 5000 & 0.0040 \\
05 & 21 & 1470 & C & 2200 & 0.0015 \\
06 & 32 & 2240 & B,E & 1100 & 0.0005 \\
07 & 12 & 840 & C,J & 5000 & 0.0060 \\
08 & 3 & 210 & C,J & 3000 & 0.0143 \\
09 & 18 & 1260 & C & 4000 & 0.0032 \\
10 & 11 & 770 & H & 908 & 0.0012 \\
11 & 32 & 2240 & A,G & 1064 & 0.0005 \\
12 & 18 & 1260 & A,B & 2599 & 0.0022 \\
\hline
\end{tabular}

a A: Ditch; B: Landslide; C: Erosion; D: Damage to concrete construction; E: Settlements; F: Damage to surface layer; G: Culverts; H: Slope failure; J: Undermining/erosion

Table 3. Vulnerability values

communication and crisis management. The floods caused most damage in Central Gudbrandsdalen. The town of Kvam experienced the worst damages, just two years after the last extensive damage flooding, and more than 200 residents were evacuated. Dovrebanen rail road was closed due to more than 160 cases of damage to the embankments, which took two weeks to repair. A large landslide impacted close to the Fåvang railroad station. Other railroad lines were also closed for several days. The main road, E6, suffered damage along with 24 county roads and more than 20 minor roads, which had to be closed for a period. As was the case in 2011, the two main roads connecting north and south, Highway 3 and European road E6, were closed at several locations. The damage costs are estimated at a total of 1200 million
Norwegian Kroner. Peak 24 hour-rainfall was for both events in the order of $100 \mathrm{~mm}$.

A detailed account of the road damages after the 2011 event is given in [5]. The total estimate is roughly 240 million NOK for the two counties of Oppland and Hedmark. The costs are given for individual road segments, as shown in Table 1. The roads segments included in Table 1 are typically 2-lane county roads (Fylkesveier) with width of 6.5 meters. To obtain dimensionless damages estimates, the damages are normalised by typical construction costs for Norwegian roads. Flood return period for adjacent rivers are extracted from [6]. Examples of the road damages are shown in Figure 5.

\section{Example case study}

This Section details the result of the application of deterministic and probabilistic calibration of the vulnerability model presented in Section 2 to the case study described in Section 3 .

\subsection{Definition and parameterization of intensity}

In the present case study, intensity is parameterized as the base-10 logarithm of the estimated return period of the observed EWE:

$$
I=\log _{10}\left(T_{R}\right)
$$

in which $T_{R}$ is the return period of estimated river discharge (in yrs). The above model, albeit arbitrarily defined, is convenient in that it yields a non-negative, linear intensity scale (as long as $T_{R}>1 \mathrm{yr}$, which is most usual). Ouput intensity values are reported in Table 2.

\subsection{Definition and parameterization of vulnerability}

In the present case study, vulnerability is defined as the ratio between the cost of the damage induced by the EWE and the cost of reconstruction of the CI. Costs of road development for communal roads can be quantified tentatively at 50,000-90,000 NOK/m. For simplicity, an average deterministic value of $70,000 \mathrm{NOK} / \mathrm{m}$ is assumed. The total lengths of road segments were obtained from a GIS-based analysis. Reconstruction costs were obtained by multiplying the lengths of the road segments by the deterministic cost per kilometer. Vulnerability was then calculated as the ratio of damage to reconstruction cost. The parameter $V_{u b}$ was set equal to unity since the cost of complete reconstruction is an upper-bound value to the cost or repair, which quantifies damage in this example. Table 3 details the assignment of vulnerability values for the examined cases. The definition of vulnerability as given herein is arbirary and case-specific, and reflects the scope of the analysis and the goal to assess the magnitude of post-event reconstruction costs. 


\subsection{Deterministic model calibration}

Deterministic calibration of the vulnerability model can be achieved by generalized least squares (GLS) regression. The regressed coefficients are estimates of central tendency, i.e., of a "mean" curve. Deterministic calibration yielded the deterministic model parameters $A_{d e t}=5.9$ and $B_{d e t}=5.96$. Figure 6 shows the deterministic vulnerability function and the source data. It is evident that deterministic calibration does not yield a conservative vulnerability function, as most source data points lie above the output vulnerability curve.

\subsection{Probabilistic model calibration}

The above result confirms that deterministic calibration is very often conceptually not adequate for engineering analysis and design purposes. As stated previously, deterministic regression yields estimates of mean functions, i.e., functions which tend to provide central estimates of relationships between independent and dependent parameters. In engineering analysis, it is most often necessary to operate with reference to a target degree of conservatism. Conservatism is related to safety and performance of engineering systems, and is an especially relevant concept in the context of critical infrastructures, for which reduced serviceability or worse - collapse, are likely to result in unacceptable consequences and risk. The target degree of conservatism is expected to increase with the criticality of the vulnerable infrastructure under investigation, as the threshold of tolerable/acceptable risk decreases with

(a) Veikledalen in the municipality of Nord Fron, Gudbrandsdalen

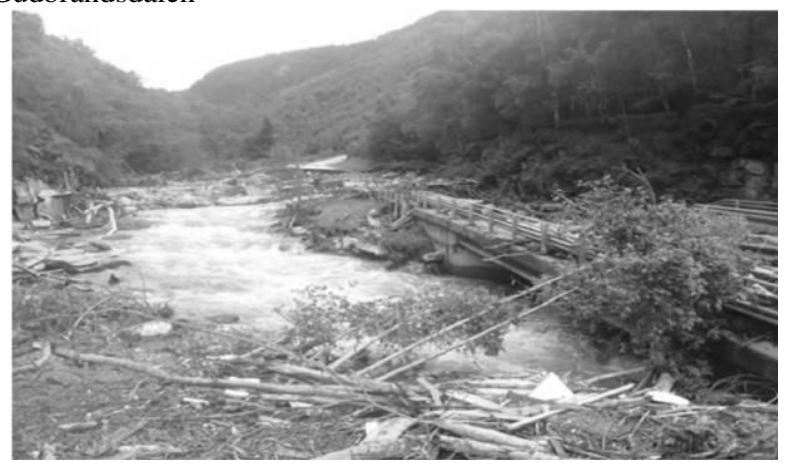

(b) Overview of Europe road E6 through Gudbrandsdalen.

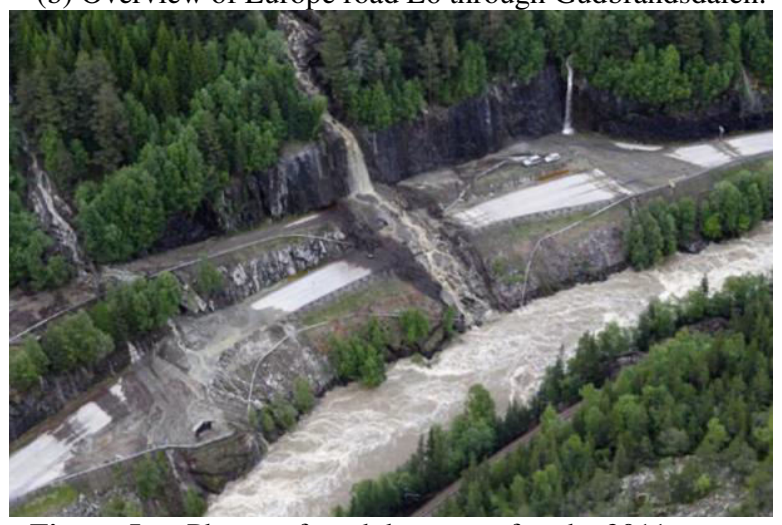

Figure 5. Photos of road damages after the 2011 event. Source: NPRA (2012). Photo: Niklas Eriksson, NPRA. increasing criticality.

Regression models are almost invariably simplifications and approximations of relationships between parameters. In other words, they are approximate, simplified models of the phenomena which they parameterize. The scatter of data points around regression models represent the indetermination in the phenomena and, in the case of the present analysis, of the domains in which intensity and vulnerability are parameterized. In quantitative terms, indetermination, vagueness and complexity are parameterized by uncertainty. A detailed treatment of uncertainty in the geosciences is not provided here. Readers are referred, for instance, to [7]. In very general terms, uncertainties can be categorized (see e.g. [7]) into aleatory (representing the "true" variability in the parameters and phenomena under investigation) and epistemic (representing, among other things: the imperfections in measurements and estimates of the parameters; the imperfections in the models; the uncertainty in statistical estimates of model parameters resulting from the limited size of data sets). Aleatory uncertainty can possibly be reduced by varying the scale of investigation of the analysis. Epistemic uncertainty can be reduced, but never completely eliminated, by increasing the size and quality of data sets and by improving models). With reference to critical infrastructures, a tentative list of sources of uncertainty can be attempted for the various dimensions of vulnerability. Some examples are shown in Table 4.

Neglecting uncertainties leads to gross simplification of the systems under investigation, and hinders a comprehensive understanding of the sensitivity of a system to the (effectively existing) indetermination in its parameters and models. Moreover, a purely deterministic analysis impedes the rational assessment of risk and target level of reliability of a system. Hence, the uncertainty-based analysis of engineering systems is receiving increasingly focused attention, as attested by the development of reliability-based design codes and by the rise of systematic risk analysis approaches.

Uncertainty-based modelling of vulnerability is achieved here using quantile regression. Quantile regression is a type of regression analysis often used in statistics and econometrics. Whereas the method of least squares results in estimates that approximate the conditional mean of the response variable given certain values of the predictor variables, quantile regression aims at estimating either the conditional median or other quantiles of the response variable [8].

Quantile regression is a most convenient and useful tool if confident estimates of conditional quantile functions are of interest. This is often the case in risk management, since conservatism and safety are conceptually related to high probabilities of non-exceedance, i.e., to high quantiles of vulnerability and risk as output variables of quantitative estimation frameworks. It is thus possible to define "characteristic vulnerability", analogously to characteristic values in modern design codes such as the Eurocodes, as values of a parameter or model explicitly related to a target probability of exceedance or nonexceedance. The selection of a characteristic value or function thus expresses the analyst's target degree of 


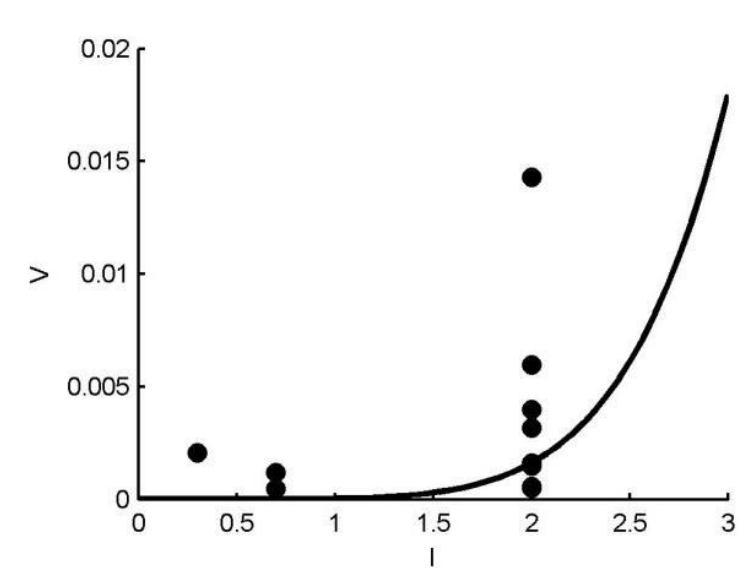

Figure 6. Deterministic calibration of the vulnerability model

conservatism, which is expected to increase with the criticality of the vulnerable infrastructure under investigation.

Quantile regression thus allows a direct estimate of characteristic vulnerability. Besides the full consistency with the fundamental concept of conservatism in engineering, quantile regression is beneficial in that it allows a more comprehensive analysis of the relationship between variables. Furthermore, quantile regression estimates are more robust against outliers in the response measurements relative to the ordinary least squares regression.

Consider the following general response model

$$
V=g(\theta, I)
$$

in which $\theta$ is an 2-sized vector denoting the set of model coefficients $[A, B], I$ is an $N$-sized vector of intensity values (independent variable) and $V$ is an $N$-sized vector of vulnerability values (dependent variable). The $p$ th regression quantile $(0<p<1)$ is defined as any solution $\theta_{p}$ to the quantile regression minimization problem

$$
\min \sum_{i=1}^{N} f_{L P} \cdot \lambda_{i}
$$

where the loss function for the $i$-th observation $(i=1, \ldots, N)$ is given by

$$
f_{L P}\left(\lambda_{i}\right)=\frac{\left|\lambda_{i}\right|+(2 p-1) \lambda_{i}}{2}
$$

and

$$
\lambda_{i}=V_{i}-g\left(\theta, I_{i}\right)
$$

is the difference between the $i$-th observed vulnerability value and model-predicted value for the $i$-th intensity value $I_{i}$.

Quantile regression implements the minimization algorithm and yields model parameters which define the characteristic vulnerability curve for the $p$-th regression

\begin{tabular}{lll}
\hline $\begin{array}{l}\text { Vulnerability } \\
\text { dimension }\end{array}$ & $\begin{array}{l}\text { Example of } \\
\text { vulnerability } \\
\text { factor }\end{array}$ & $\begin{array}{l}\text { Example of source of } \\
\text { uncertainty }\end{array}$ \\
\hline Ecological & $\begin{array}{l}\text { Area planning and } \\
\text { management } \\
\text { influence the } \\
\text { absorbing capacity } \\
\text { of nature based } \\
\text { systems to handle } \\
\text { or reduce the } \\
\text { effect of extreme } \\
\text { weather }\end{array}$ & $\begin{array}{l}\text { Uncertainty in state of } \\
\text { nature based systems } \\
\text { of nature based system } \\
\text { for example on water } \\
\text { absorption, soil } \\
\text { stabilisation or wind } \\
\text { reduction }\end{array}$ \\
& $\begin{array}{l}\text { Inadequacy of } \\
\text { back-up systems }\end{array}$ & $\begin{array}{l}\text { Uncertainty in } \\
\text { whether back-up } \\
\text { system will function }\end{array}$ \\
& & $\begin{array}{l}\text { as expected due to } \\
\text { lack of } \\
\text { testing/verification } \\
\text { old age/lack of } \\
\text { maintenance }\end{array}$ \\
& & outdated technology
\end{tabular}

Economic Less affluent Uncertainty in the link societies will between cost of a CI typically have less and its resilience to resources to EWE manage the risk

Societal Dependency of CI on the availability of specialists

Uncertainty in the actual effect of specialist competence in case of high intensity EWEs Uncertainty in availability of experts when EWE actual hits, and to which degree they are prepared for the event

Cultural Level of trust and Uncertainty in how openness in society will influence level of collaboration between stakeholders and knowledge sharing of possible vulnerability, interactions and cascading effects

Institutional Institutional Uncertainty in the fragmented responsibilities degree that the EWE will cause cascading and indirect effects that will reveal the absence of interinstitutional coordination

Table 4. Examples of sources of uncertainty for different dimensions of vulnerability 


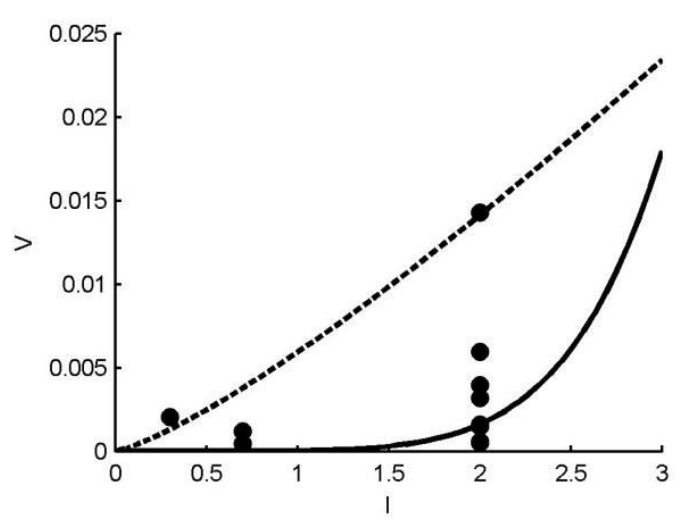

Figure 7. Deterministic and characteristic vulnerability functions

quantile (corresponding essentially to a probability of non-exceedance).

Quantile regression was performed on the data for a characteristic quantile of 0.95 . Figure 7 shows comparatively the deterministic and characteristic vulnerability curves, the latter referring to a quantile (probability of non-exceedance) of 0.95 . The values of model parameters corresponding to the characteristic vulnerability curve are $A_{Q R}=58.5, B_{Q R}=1.26$.

\section{Analysis and discussion of results}

The quantitative investigation of vulnerability as proposed in this paper allows a fully quantitative estimation of risk, provided that hazard and exposure are also addressed quantitatively. Moreover, the quantile regression-based approach allows the objective association of a vulnerability function with a probability of exceedance, thus allowing the conceptual inclusion of the target degree of conservatism depending on factors such as the criticality of the infrastructure, regulatory constraints, political decisions, etc.

Care should always be placed to not extrapolate results beyond the range of intensity values which were used in the calibration process. In the present case study, the deterministic and the characteristic vulnerability models can be applied with confidence for $I \leq 2$, since no points corresponding to higher intensity are available.

Despite the markedly quantitative character of the approach, it is paramount to remark that the quantitative parameterization of intensity and vulnerability relies on user's choices and judgment. Moreover, subjectivity and indetermination are always present in the parameterization process due to the epistemic uncertainty and to the subjectivity which is inherent to expert assignment of quantitative values. In the case study presented herein, for instance, there is subjectivity in the return periods which are associated with the flooding events. This reflects in epistemic uncertainty in intensity values, as each data point could be shifted along the horizontal axis and, thus contribute to different results of deterministic and quantile regression.

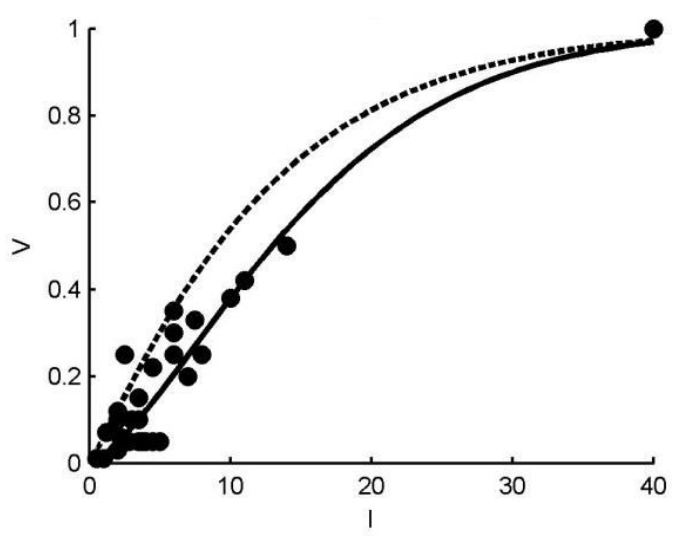

Figure 8. Deterministic and probabilistic calibration of the vulnerability model for the tsunami data

It is also important to note that quantitative vulnerability values must be framed within the specific set of operational definitions which lie at the base of their parameterization. Consequently, the interpretation of their magnitude and the direct or indirect outputs of their quantitative modelling must be consistent with such definitions. For instance, the vulnerability model defined herein can only be employed to estimate reconstruction costs, and cannot serve as a means to assess the risk to persons travelling on the roads or to the estimation of the downtime of the road infrastructure.

A second application is presented here to provide an example of a data set spanning over a wider range of intensity and vulnerability. The example refers to the vulnerability of persons to tsunami hazard [9]. The data have been collected from different sources reporting fatality rates associated to inundation heights from tsunamis in lakes and fjords in western Norway, from the December 2004 Indian Ocean tsunami and from the July 2006 Java tsunami. In this case, intensity is given by the run-up (in meters), while vulnerability is defined as the ratio of fatalities to the total exposed population (i.e., the persons present in the study area at the time of occurrence of the event). The deterministic and probabilistic vulnerability curves are shown along with the source data in 8 . With respect to the case study developed in this paper, there is the availability of a high-vulnerability point corresponding to the tragic scenario of the entire population of 34 persons losing their lives in the small Norwegian community of Ytre Nesdal, where the Loen tsunami event of 1905 reached a run-up of 40 meters.

The vulnerability models are not static, and can be updated as new data become available, provided that data are homogeneous in terms of at least the operational definitions of intensity and vulnerability, and the reference area in which they are collected.

This paper will hopefully serve as an example which may contribute to stimulate and facilitate a more systematic collection and organization of quantitative data regarding damage to critical infrastructures from hazardous events such as flooding, in the broader perspective of an increasingly objective and quantitative approach to risk analysis. 


\section{Acknowledgments}

This paper stems from the research conducted in the framework of the project "INTACT - Impact of extreme weather on critical infrastructure". The project is cofounded by the European Union under the 7th Framework Programme, with the Grant agreement number 606799.

\section{References}

1. DSB (2012a). Samfunnets sårbarhet overfor bortfall av elektronisk kommunikasjon. (http://dsb.no/Global/Publikasjoner/2012/Rappor t/bortfall_elektronisk_kommunikasjon.pdf)

2. DSB (2012b). Oppfølging etter flommen i juni 2011

(http://www.dsb.no/Global/Publikasjoner/2012/ Rapport/flom_juni_2011.pdf)

3. DSB (2013). Evaluering av myndighetenes forebyggingsarbeid og håndtering av flommen $\mathrm{i}$ mai 2013. http://www.dsb.no/Global/Publikasjoner/2013/R apport/Flomevaluering_2013.pdf

4. Roald, L.A. (2015). Flommen på Østlandet i mai 2013. NVE report No. 21, March 2015. (http://www.nve.no/PageFiles/6746/78\%20Flom men $\% 20$ p $\%$ C3\%A5\%20\%C3\%98stlandet $\% 20 \mathrm{i}$ \%20mai\%202013.pdf)

5. NPRA (2012). Rapport om skadeflom i Pinshelga 2011. Hedmark og Oppland. Norwegian Public Roads Administration, Region East, 25.2.2012. (http://brage.bibsys.no/xmlui/bitstream/handle/1 1250/190571/Rapport\%20om\%20skadeflom\%2 0i\%20pinshelga\%202011_Statens\%20vegvesen $\% 20$ Region $\% 20 \%$ c3\%b8st.pdf? sequence=1\&is Allowed=y)

6. Kleivane, I. (2011). Flaumen i Sør-Noreg, juni 2011. Norwegian Water Resources and Energy Directorate (NVE) document 11/2011. (http://www.nve.no/PageFiles/6746/92\%20Flau men_i_S\%C3\%B8rNoreg_juni_2011.pdf)

7. Uzielli, M., Lacasse, S., Nadim, F. and Phoon, K.K. (2007). Soil variability analysis for geotechnical practice. T.S. Tan, K.K. Phoon, D.W. Hight \& S. Leroueil (eds.), Proceedings of the Second International Workshop on Characterisation and Engineering Properties of Natural Soils. Singapore, November 29 December 1, 2006. The Netherlands: Taylor \& Francis.

8. Yu, K., Lu, Z., Stander, J. (2003). Quantile regression: applications and current research areas. The Statistician, Vol. 52, Part 3: 331-350.

9. Eidsvig, U.M., Medina-Cetina, Z., Kveldsvik, V., Glimsdal, S., Harbitz, C.B. and Sandersen, F. (2011). Risk assessment of a tsunamigenic rockslide at Åknes. Natural Hazards, Vol. 56:529-545. 